\title{
Determination of low environmental free cyanide concentrations in freshwaters
}

\author{
Burkhard Knopf $^{1}$ (D) $\cdot$ Heinz Rüdel ${ }^{1}$ (D) Dirk Hansknecht ${ }^{1} \cdot$ Thorsten Klawonn $^{1} \cdot$ Knut Kreuzer $^{2}$
}

Received: 23 July 2020 / Accepted: 10 December 2020 / Published online: 17 December 2020

(C) The Author(s) 2020

\begin{abstract}
Cyanide compounds are naturally emitted into the environment in low levels by degradation processes or emitted from anthropogenic sources. In surface water, complex cyanide compounds as well as "free cyanide" are present. The latter term covers hydrogen cyanide and cyanide compounds which easily liberate hydrogen cyanide under slightly acidic conditions. Especially free cyanide may cause adverse effects in the environment. To exclude negative impacts on freshwater systems, in the context of the European Water Framework Directive (WFD), preventive regulatory activities for free cyanide are currently under discussion. However, established analytical methods for quantification of free cyanide only obtain limits of quantification (LOQs) in the range of $1 \mu \mathrm{g} \mathrm{L}^{-1}$. Thus, these methods are not sufficiently sensitive for a potential environmental quality standard (EQS) compliance monitoring at water concentrations below the current predicted no effect concentration (PNEC) level of free cyanide. In the present study, a standardized continuous flow analysis (CFA) method for quantification of low free cyanide concentrations was adapted by applying a special system which allows an ultra-sensitive photometric detection of a colored cyanide derivative. By this means, LOQs in a range of one magnitude below the PNEC are achievable. The method was validated according to ISO/ IEC 17025 requirements. Free cyanide concentrations in tested surface water samples from a small river and a barrier lake with low anthropogenic influences were very low and clearly below the PNEC. The results prove that the adapted CFA method is suitable for the analysis of low concentration free cyanide in freshwaters and appropriate for a possible EQS compliance monitoring.
\end{abstract}

Keywords Free cyanide · Continuous flow analysis · Environmental quality standard · Surface water · Environmental monitoring · Compliance monitoring $\cdot$ Water framework directive

\section{Introduction}

In environmental waters, cyanide can occur as entity in simple and complex compounds (Jaszczak et al. 2017). Free cyanide, also designated as easily liberatable cyanide, is defined as the sum of cyanide ions and cyanide bound in weak metal cyanide complexes that liberate hydrogen cyanide at a $\mathrm{pH}$ of about 4 (ISO 2012). It exists in fresh water systems in low concentrations and originates from naturally occurring degradation

Responsible Editor: Xianliang Yi

Burkhard Knopf

burkhard.knopf@ime.fraunhofer.de

1 Fraunhofer Institute for Molecular Biology and Applied Ecology IME, Schmallenberg, Germany

2 Röhm GmbH, Deutsche-Telekom-Allee, Darmstadt, Germany processes of plants and microbes. In contrast to information on total cyanide covering simple and complex compounds, information on background levels of the toxicological relevant free cyanide in freshwater systems is extremely sparse. Krutz (1981), for example, analyzed free cyanide in the range of $0.1-10 \mu \mathrm{g} \mathrm{L}^{-1}$ in two small rivers with seasonal fluctuations in Germany. Beside natural origins, cyanide compounds may be emitted from anthropogenic sources, like mining operations, metallurgic industry, and wastewater treatment plants or during fires (Jaszczak et al. 2017).

Free cyanide anions are highly toxic towards aquatic organisms ((Australian Water Association (2000); (ECETOC 2007)). For example, the current predicted no effect concentration (PNEC) level for freshwater organisms under European chemicals' management directive REACh is as low as $1 \mathrm{\mu g} \mathrm{L}^{-1}$ (ECHA 2020). The European Water Framework Directive 2000/60/EC (WFD) established a "targeted EU-wide monitoring of substances of possible 
concern" for the aquatic environment via a watch list mechanism (EU 2013; EU 2015a). Consultations on such a multiannual monitoring for free cyanide are currently ongoing and, below other aspects, refer to the current unavailability of a reliable analytical method of sufficient sensitivity, i.e., one order of magnitude below the PNEC (EU 2015b; Loos et al. 2018; Peters et al. 2012). This concentration range is considered relevant for a potential future environmental quality standard (EQS) in several evaluations (Sorokin et al. 2012) (EU 2015b; Peters et al. 2012) which should prevent adverse effects by androgenic released substances towards pelagic communities of freshwater organisms. The respective WFD compliance monitoring requires analytical methods with a limit of quantification (LOQ) of at least $30 \%$ of the EQS and a maximum measurement uncertainty of $50 \%$ to ensure the reliable quantification of target compounds in waters (EC 2009). Thus, there is a strong demand for an analytical method allowing free cyanide determinations in this low concentration range.

Since present analytical methods for free cyanides (e.g., spectrometric and electrochemical methods as well as mass spectrometry, ion and gas chromatographic procedures) only can achieve LOQs above $1 \mu \mathrm{g} \mathrm{L}^{-1}$ (see e.g., review by Ma and Dasgupta (2010)), a more sensitive procedure for the determination of low levels of free cyanide was required. To this end, a standardized continuous flow analysis (CFA) method was adapted to a higher sensitivity, validated in the laboratory and with samples from a river and a barrier lake, and implemented for routine application. The optimized CFA method with photometric quantification is based on international standard ISO 14403-2 (ISO 2012) and has an application range of 10 $100 \mu \mathrm{g} \mathrm{L}^{-1}$.

The validation and application of the adapted CFA method for the quantification of low levels of free cyanide in surface waters according to WFD technical requirements were initiated and funded by a consortium of European industry associations (CONCAWE, Cefic, Eurofer, and Euromines).

\section{Materials and methods}

\section{Instrumentation}

As device for the sensitive determination of free cyanide, the CFA system San++ Automated Wet Chemistry Analyzer (Skalar Analytical B.V., Breda, The Netherlands), including an autosampler and a computer with a dedicated software for the calculation of free cyanide concentrations of samples, was chosen. This instrument allows an automatic distilling of free cyanide from aqueous samples for separation and enrichment of the cyanide prior to a chemical reaction forming a dye for the subsequent photometric detection. A special cuvette (glass fiber) with a length of $50 \mathrm{~cm}$ was installed to improve the sensitivity: According to the Beer-Lambert law, the layer thickness is proportional to the extinction (absorbance of the dye) thus improving the sensitivity by a factor 50 in comparison to a CFA instrument with a standard 1-cm cuvette. The standard ISO 14403-2 (ISO 2012) explicitly mentions the option to enhance the sensitivity of the method by applying a detection cell with a larger optical path length so that the instrument is compliant with the standard.

\section{Standards and reagents}

Principally, for CFA, the use of a tenside in the carrier solution is required for separating discrete volumes by air segments (bubbles). However, based on pre-tests, the non-ionic tenside polyoxyethylene dodecylether (CAS No. 9002-92-0) originally proposed in standard ISO 14403-2 (ISO 2012) was substituted by the ionic tenside dodecyl diphenyloxide disulphanated sodium salt (CAS No. 119345-04-9; trade name FFD6). FFD6 was more suitable for maintaining a low and stable background of the applied CFA instrument with the $50-\mathrm{cm}$ cuvette than polyoxyethylene dodecylether. FFD6 seems generally appropriate as tenside for this purpose and already is used in another CFA application (for orthophosphate analysis, ISO 15681-2).

Reagents were of "for analysis" quality: citric acid monohydrate (purchased from Honeywell Fluka, via Fisher Scientific GmbH, Schwerte, Germany), zinc sulfate heptahydrate (Merck KGaA, Darmstadt, Germany), potassium hydrogen phthalate (Merck), FFD6 (provided as 25-50\% solution in water, from Skalar Analytical), sodium hydroxide (Chemsolute, Th. Geyer GmbH, Renningen, Germany), hydrochloric acid (J.T. Baker, via Fisher Scientific), chloramineT trihydrate (Merck), 1,3-dimethyl barbituric acid (SigmaAldrich, via Merck), and 4-pyridine carboxylic acid (Merck). Ultrapure water with a resistivity of $>18.2 \mathrm{M} \Omega \mathrm{cm}$ was prepared by deionization of tap water using a Purelab Ultra device (ELGA Veolia, Celle, Germany).

Certified cyanide standard solutions were obtained from three different providers (certified concentrations in brackets, prepared from potassium cyanide salt of $>96 \%$ purity in $0.1 \%$ sodium hydroxide solution in purified water): Alfa Aesar, via Fisher Scientific $\left(1000 \pm 5 \mathrm{mg} \mathrm{L}^{-1}\right)$; ULTRA Scientific, via Agilent, Waldbronn, Germany $\left(1005 \pm 6 \mathrm{mg} \mathrm{L}^{-1}\right)$; and LGC Standards GmbH, Wesel, Germany (1000 $\mathrm{mg} \mathrm{L}^{-1} \pm 0.5 \%$ relative uncertainty). Each calibration prepared with a certified cyanide standard from one source was verified by analysis of diluted quality control standards derived from a certified standard from a second source.

Reagent solutions were prepared following the instructions of the CFA instrument SAN++ method for the analysis of free distillable cyanide (Skalar Analytical 2015). Compositions are based on ISO 14403-2 and are given there in detail (ISO 2012). However, as described above, polyoxyethylene 
dodecylether was substituted by the same volume of FFD6 solution for preparation of the buffer solution.

The prepared solutions were stored at room temperature in the dark and refreshed weekly according to the instructions in ISO 14403-2 (ISO 2012).

Gas bubbles in the solutions passing the glass fiber detection cell of the CFA instrument may reduce sensitivity by increasing background noise and thus the LOQ. To avoid this effect, all solutions were percolated with helium before a measurement series in addition to a treatment by sonication as recommended by the manufacturer.

\section{Analytical method}

The CFA method for the determination of free cyanide is described in detail in standard ISO 14403-2 (ISO 2012). In brief, first, zinc sulfate solution is added to the water sample for precipitation of iron cyanides as zinc cyanoferrate complexes. Then, the solution is heated to $125^{\circ} \mathrm{C}$ at a $\mathrm{pH}$ of 3.8 to separate and enrich the free cyanide as hydrogen cyanide by distillation. The distilled hydrogen cyanide reacts with chloramine-T yielding cyanogen chloride which then forms a purple dye with pyridine-4-carboxylic acid (isonicotinic acid) and 1,3-dimethyl barbituric acid. The formed dye allows the sensitive photometric detection at $600 \mathrm{~nm}$ with an appropriate instrument (see Fig. 1).

For the basic validation (calculation of lowest possible LOD and LOQ), the CFA instrument was calibrated with the following equidistant cyanide standard concentrations (dilutions of a certified cyanide standard; dilution factor of high to low standard not more than 1:100): $0.000(0.01 \mathrm{M}$ sodium hydroxide in ultrapure water), $0.100,0.200,0.300,0.400$, $0.500,0.600,0.700,0.800,0.900$, and $1.000 \mu \mathrm{g} \mathrm{L}^{-1}$. All standards were filled up with a $0.01 \mathrm{M}$ sodium hydroxide solution (in ultrapure water). For all further measurement series (reproducibility, precision, environmental samples, etc.), calibrations in the relevant concentration ranges were performed (e.g., with calibration points of $0.000,0.100,0.250,0.500$, $0.750,1.000,1.250$, and $1.500 \mu \mathrm{g} \mathrm{L}^{-1}$ ). The accuracy of the applied pipettes was verified regularly. The diluted standards were prepared freshly on a daily basis.

The CFA instrument's software was used for the calculation of the calibration lines from the measured diluted standards (linear regression; correlation coefficients at least 0.995). Cyanide concentrations of investigated water samples were calculated by the software from the daily measured calibration line.

\section{Sample stabilization and storage}

Aqueous solutions (including calibration standards) were stabilized by alkalinization to prevent losses of free cyanide. Following the procedure of the ISO 14403-2 standard (ISO
2012), samples were stabilized immediately after sampling by adjusting the $\mathrm{pH}$ to $>12$ (addition of small volumes of $0.01 \mathrm{M}$ sodium hydroxide solution). According to the ISO 14403-2 standard, the $\mathrm{pH}$-adjusted samples are stable for up to 1 week. Furthermore, the stability for up to 1 week could be verified in stabilized free cyanide-spiked samples in the present study.

River and barrier lake water samples were taken at different seasons in 2016. They were stabilized as described above and stored at $4{ }^{\circ} \mathrm{C}$ in the dark. The appropriateness of these conditions was tested and confirmed by analysis of positive controls containing low amounts of free cyanide stored in the same manner.

\section{Prevention of interferences}

Oxidizing compounds, or sulfides at concentration $\geq 100 \mathrm{mg} \mathrm{L}^{-1}$, might interfere with the formation of the dye needed for photometric determination of free cyanide according to ISO 14403-2 (ISO 2012). Therefore, possible oxidizers were determined in samples as described in ISO 14403-2 (ISO 2012) by using potassium iodide starch paper (MachereyNagel, Düren, Germany). No staining of the paper was observable in any sample. Total sulfur concentrations of only 100-700 $\mathrm{g} \mathrm{L} \mathrm{L}^{-1}$ were measured in samples by ICP-OES following standard ISO 11885 (ISO 2007). Thus, no interferences were expected from oxidizers or from the detected sulfur compounds in the samples.

\section{Validation of the analytical method}

For method validation, the following parameters were determined: limits of detection and quantification (LOD, LOQ), selectivity, reproducibility, repeatability, measurement uncertainty, and performance in an interlaboratory comparison. The validation followed the requirements of standard ISO/IEC 17025 (ISO/IEC 2005). Moreover, the method was tested during sampling campaigns with field samples.

\section{Results and discussion}

\section{Validation}

\section{LOD and LOQ determination}

A main objective in method validation is the determination of the LOD and LOQ. According to general WFD quality requirements, an LOQ of $\leq 30 \%$ of the EQS has to be achieved (EC 2009). Since the most recent proposal for a potential EQS for free cyanide (Loos et al. 2018) considered a safety factor of 2 to the PNEC value of $1 \mu \mathrm{g} \mathrm{L}{ }^{-1}$, the targeted LOQ level of the method was a magnitude below the PNEC (i.e., about $\left.0.15 \mu \mathrm{g} \mathrm{L}^{-1}\right)$. 


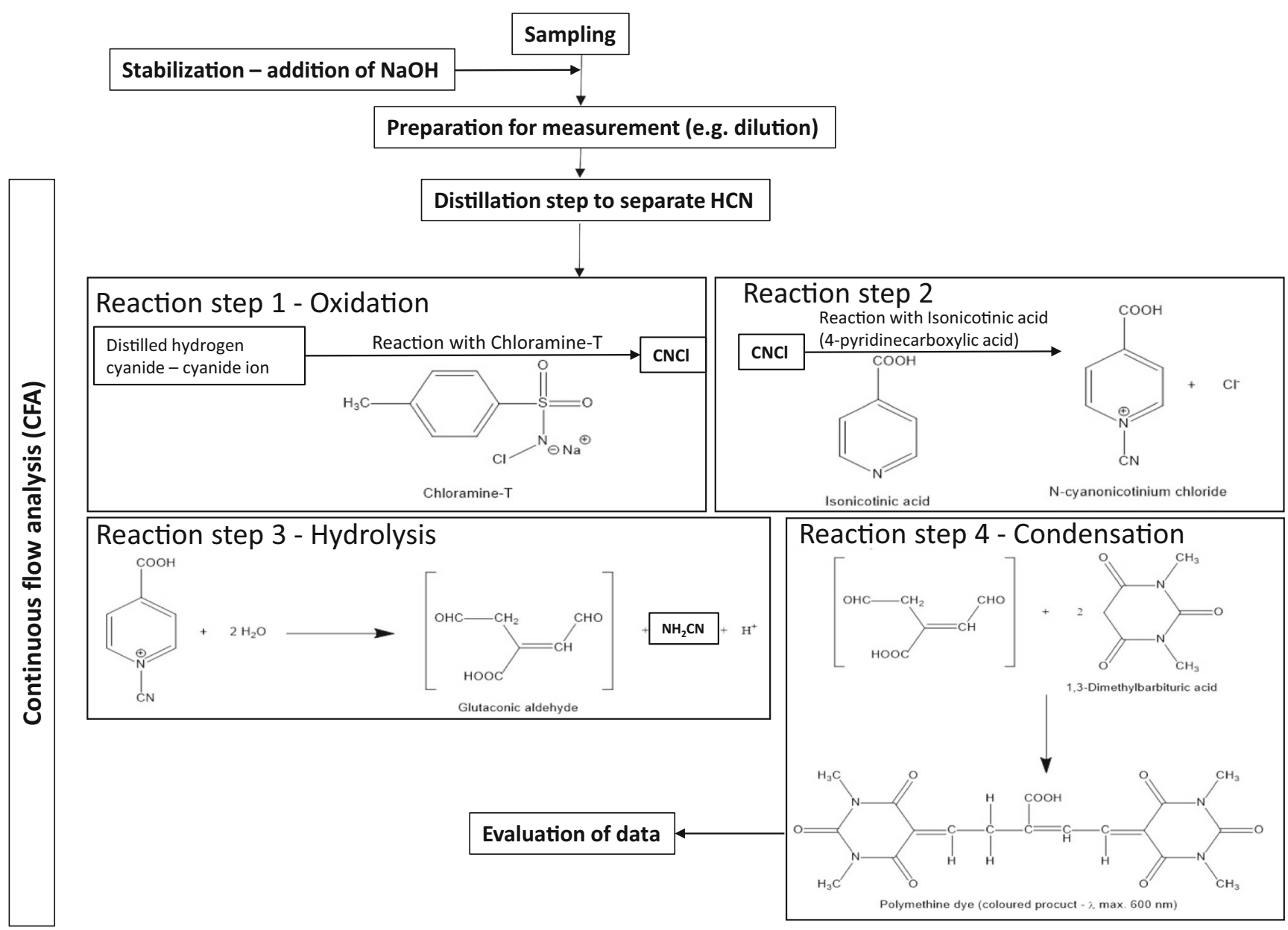

Fig. 1 Schematic diagram of the analytical procedure (from sampling to evaluation of data) and the chemical reactions for the dye formation (Maranna et al. 2018; modified scheme)

Determinations of the LOD and LOQ (calculated as 3 * LOD) were performed according to the German standard DIN 32645 (DIN 2008). The respective principles that are described in Geiss and Einax (2001) allow the LOD determination via two alternative approaches. The direct method for LOD determination is based on the analysis of blanks. The indirect method is based on the data of a calibration line and thus yields an LOD for the selected working range including the uncertainty of the calibration.

The applied method blanks for the direct LOD determination method consisted of ultrapure water which was alkalinized with sodium hydroxide solution to a target $\mathrm{pH}$ value of 12 . Two separate basic LOD determinations according to DIN 32645 (DIN 2008) were performed, so that two values were obtained. Measurements under optimal laboratory conditions led to LODs of 0.016 and $0.028 \mu \mathrm{g} \mathrm{L}^{-1}$ cyanide, and LOQs of 0.053 and $0.092 \mu \mathrm{g} \mathrm{L}^{-1}$ cyanide (95\% confidence level).

For the indirect method for the determination of the LOD, the calibration data were evaluated. The calibration range was lower than the working range for measurements to be performed later in real environmental samples. Therefore, the indirect method provides also a lower LOD compared to the LOD gained for higher calibration ranges. In the indirect method, LODs/LOQs calculated according to DIN 32645 (DIN 2008) were $0.025 / 0.037 \mu \mathrm{g} \mathrm{L}^{-1}$ (two individual measurement series) and $0.050 / 0.074 \mu \mathrm{g} \mathrm{L}^{-1}$, respectively. These calculations were performed for a confidence level of $95 \%$. For both methods (direct and indirect), comparable LODs and LOQs were obtained as required in DIN 32645 (DIN 2008), proving that a required LOQ of at least $0.15 \mu \mathrm{g} \mathrm{L}^{-1}$ for the quantification of free cyanide is achievable with the CFA system San++. Optimal conditions were applied for the measurements used for calculation of LOD and LOQ (e.g., degassing with helium, use of FDP6 as tenside, blank sample inserted after each sample).

For all further measurements for method validation, the LODs and LOQs were calculated by the indirect method (calibration method) for each measurement series. According to these results, a reproducible LOQ of $0.1-0.3 \mu \mathrm{g} \mathrm{L}^{-1}$ for the quantification of free cyanide using this CFA method can be obtained under realistic routine laboratory conditions. 


\section{Selectivity}

The selectivity for photometric detection of free cyanide at the specific wavelength of $600 \mathrm{~nm}$ is based on a reaction of cyanide yielding a specific dye according to international standard DIN EN ISO 14403-2.

\section{Precision and repeatability}

For investigation of the precision, diluted alkalinized aqueous certified standards were measured. The limits of recoveries were set to $100 \pm 15 \%$ for values equal to or above 2 times the concentration of the LOQ level and $100 \pm 30 \%$ for concentration values above LOD but below concentrations of 2 times the LOQ level. To check the variance precision, samples with nominal concentrations of $0.100 \mu \mathrm{g} \mathrm{L}^{-1}$ (required recovery limits $100 \pm 30 \%)$ and $0.75 \mu \mathrm{g} \mathrm{L}^{-1}(100 \pm 15 \%)$ were measured (with $n=10$ each). The precision results for a confidence level of $95 \%$ were $0.126 \pm 0.007 \mu \mathrm{g} \mathrm{L}^{-1}$ (nominal $0.100 \mu \mathrm{g} \mathrm{L}^{-1}$ cyanide) and $0.724 \pm 0.025 \mu \mathrm{g} \mathrm{L}^{-1}$ (nominal $0.750 \mu \mathrm{g} \mathrm{L}^{-1}$ cyanide).

To determine the repeatability, samples with nominal concentrations of $0.100 \mu \mathrm{g} \mathrm{L}^{-1}, 0.250 \mu \mathrm{g} \mathrm{L}^{-1}, 0.500 \mu \mathrm{g} \mathrm{L}^{-1}$, and $0.750 \mu \mathrm{g} \mathrm{L}^{-1}$ cyanide were investigated ( $n=20$, respectively). Mean measured values were $0.107 \pm 0.019 \mu \mathrm{g} \mathrm{L}^{-1}, 0.187 \pm$ $0.019 \mu \mathrm{g} \mathrm{L}^{-1}, 0.548 \pm 0.029 \mu \mathrm{g} \mathrm{L}^{-1}$, and $0.724 \pm$ $0.025 \mu \mathrm{g} \mathrm{L}^{-1}$. The nominal $0.100 \mu \mathrm{g} \mathrm{L}^{-1}$ cyanide concentration level was below the LOQ concentration but above the LOD concentration so that the quality control parameters were set to $100 \pm 30 \%$, whereas at other concentrations, recoveries of $100 \pm 15 \%$ were required.

As the recoveries of all measurements were within the required range for the defined parameters, it was concluded that the method allows to quantify cyanide with the required precision and repeatability.

\section{Reproducibility}

Three measurement series were performed by three different operators on different days for determining the reproducibility of the method. The quality criteria for the relative standard deviation (RSD) for levels above the LOQ were set as maximum of $10 \%$ for a sufficient reproducibility $(20 \%$ for levels < LOQ but $>$ LOD). Diluted certified cyanide standards containing $0.100 \mu \mathrm{g} \mathrm{L}^{-1}$ (< LOQ but > LOD) and $0.500 \mu \mathrm{g} \mathrm{L}^{-1}$ (> LOQ) were measured with $n=10$ each. For the individual measurements, RSD was in the range of $7.09-18.4 \%$ for $0.100 \mu \mathrm{g} \mathrm{L}^{-1}$ and $2.18-5.15 \%$ for $0.500 \mu \mathrm{g} \mathrm{L}^{-1}$ cyanide, respectively. The total RSD over all samples ( $n=30$ in total) was $19.1 \%\left(0.100 \mu \mathrm{g} \mathrm{L}^{-1}\right)$ and $6.34 \%\left(0.500 \mu \mathrm{g} \mathrm{L}^{-1}\right)$. The requirements for reproducibility were fulfilled. As the reproducibility is within the range of the quality assurance requirements for the defined parameters, it is concluded that the method allows to quantify cyanide with the required precision and reproducibility.

The laboratory participated in an interlaboratory comparison organized by IFA (Department of Agrobiotechnology, Tulln, Austria). Two samples of cyanide-spiked synthetic watersimulating environmental conditions were received. The nominal values for cyanide of these samples were $0.056 \pm$ $0.002 \mathrm{mg} / \mathrm{L}$ and $0.042 \pm 0.002 \mathrm{mg} / \mathrm{L}$. After analyzing with the final protocol, $0.054 \pm 0.006 \mathrm{mg} / \mathrm{L}$ and $0.043 \pm 0.004 \mathrm{mg} / \mathrm{L}$ cyanide were found with the CFA method (recoveries of $96 \%$ and $102 \%)$. The interlaboratory comparison yielded excellent $z-$ scores of -0.20 and 0.13 , respectively, for the samples $(z-$ scores $>-2<\mathrm{z}<2$ are regarded as satisfactory).

\section{Measurement uncertainty}

The measurement uncertainty was determined according to the NORDTEST procedure (Magnusson et al. 2012). The NORDTEST method considers both the bias of the measurement (random effects) and the bias of the laboratory (possible systematic error) for the calculation of measurement uncertainty. Extended measurement uncertainties (coverage factor of 2) of $\pm 41 \%$ for samples between 2 times the concentration of the LOD and the LOQ and of $\pm 21 \%$ for samples with concentrations above the LOQ were determined for the applied CFA method.

\section{External review}

After completion of the method validation, DAkkS (Deutsche Akkreditierungsstelle, i.e., Germany's National Accreditation Body) inspected the laboratory and the regarding written documents to examine a possible accreditation of the CFA method for determination of free cyanide. After review, the laboratory received the accreditation according to ISO/IEC 17025 (ISO/IEC 2005) for the implemented method for analysis of free cyanide.

The summarized validation information is shown in Table S1 (Supplementary Information).

\section{1st field test}

For testing the validated method in natural surface waters, samples from two sampling campaigns performed within 1 month during the winter/spring season covering five different sampling sites from the river Lenne, Germany were applied. Sampling sites were at the spring (\#1), upstream the industrial area of the city of Schmallenberg (\#2), the industrial area itself (\#3), downstream the industrial area (\#4), and downstream sampling site no. 4 (\#5). Geo-coordinates are given in Table S2 (Supplementary Information).

Table 1 shows the amount of free cyanide in samples stabilized at a $\mathrm{pH}$ value of 12 , measured $24 \mathrm{~h}$ after sampling 
Table 1 Free cyanide concentrations in samples from river Lenne at different sampling sites during the two sampling campaigns of the 1 st field test (measured $24 \mathrm{~h}$ after sampling, stabilized at $\mathrm{pH} 12$ and stored at $4{ }^{\circ} \mathrm{C}$ in the dark)

\begin{tabular}{llllll}
\hline $\begin{array}{l}\text { Sampling } \\
\text { site no. }\end{array}$ & $\begin{array}{l}\text { LOD } \\
\left(\mu \mathrm{g} \mathrm{L}^{-1}\right)\end{array}$ & $\begin{array}{l}\text { LOQ } \\
\left(\mu \mathrm{g} \mathrm{L}^{-1}\right)\end{array}$ & $\begin{array}{l}\text { Measured free } \\
\text { cyanide } \\
\text { concentration } \\
\left(\mu \mathrm{g} \mathrm{L}^{-1}\right)\end{array}$ & $\begin{array}{l}\text { Reported free cyanide } \\
\text { concentration }\left(\mu \mathrm{g} \mathrm{L}^{-1}\right)^{\#}\end{array}$ & $\begin{array}{l}\text { Range of extended } \\
\text { measurement } \\
\text { uncertainty }( \pm)\end{array}$ \\
\hline
\end{tabular}

1st sampling campaign (February/March sampling)

$\begin{array}{lllllll}1 & 0.051 & 0.188 & 0.034 & <\text { LOD } & 0.051 & \$ \\ 2 & 0.033 & 0.124 & 0.115 & <\text { LOQ } & 0.115 & 0.047 \\ 3 & 0.060 & 0.232 & 0.129 & <\text { LOQ } & 0.129 & 0.053 \\ 4 & 0.060 & 0.232 & 0.101 & <\text { LOQ } & 0.101 & 0.041 \\ 5 & 0.033 & 0.124 & 0.135 & 0.135 & 0.135 & 0.028 \\ \text { 2nd sampling campaign (March sampling) } & & & \$ \\ 1 & 0.112 & 0.461 & 0.067 & <\text { LOD } & 0.112 & 0.043 \\ 2 & 0.042 & 0.154 & 0.105 & <\text { LOQ } & 0.105 & 0.064 \\ 3 & 0.046 & 0.168 & 0.156 & <\text { LOQ } & 0.156 & 0.065 \\ 4 & 0.046 & 0.168 & 0.158 & <\text { LOQ } & 0.158 & 0.035 \\ 5 & 0.042 & 0.154 & 0.085 & <\text { LOQ } & 0.085 & \\ \text { \# Concentrations < LOD were set to the respective LOD of the measurement series; for concentrations between } \\ \text { FoD and LOQ, the measured concentrations are given } \\ \text { For concentrations below LOD, no measurement uncertainty could be calculated }\end{array}$

(storage at $4{ }^{\circ} \mathrm{C}$ in the dark) of the 1 st field test. The concentrations of free cyanide in the natural water samples from river Lenne were low and mainly below the calculated LOD/LOQ of the respective measurement series. Therefore, values below LODs were set to the respective LOD, while for values between LOD and LOQ, the actual measured concentrations are reported. The results prove that a realistic LOQ in the range of $0.1-0.3 \mu \mathrm{g} \mathrm{L}^{-1}$ during daily routine analysis of environmental samples from freshwaters can be achieved with the implemented CFA method.

\section{2nd field test}

After the 1st field test, a second approach was performed with samples from a barrier lake (Esmecke Stausee, two sampling sites) as well as from two sampling sites of the 1st field test during the fall season. Sampling sites were at Esmecke Barrier Lake (sites A and B), and at the river Lenne downstream the industrial area of Schmallenberg (site C; similar to site \#4 of the 1 st field test) as well as further downstream sampling site C (D; similar to site \#5 of the 1st field test). Geo-coordinates are given in Table S3 (Supplementary Information). As for the 1st field test, measurements were divided into two campaigns. For the 1st sampling campaign of the 2nd field test, samples were taken at different times of the day to investigate daytime effects, whereas for the 2 nd campaign, only samples taken around midday were considered.

Table 2 shows the amount of free cyanide in samples stabilized at $\mathrm{pH} 12$, measured $24 \mathrm{~h}$ after sampling (storage at $4{ }^{\circ} \mathrm{C}$ in the dark) of the 2 nd field test. The concentrations of free cyanide in the natural water samples from the barrier lake and the river Lenne were low and in some cases below the calculated LOD/LOQ of the respective measurement series. Therefore, values below LODs were set to the respective LOD, while for values between LOD and LOQ, the actual measured concentrations are reported. The results of the 2 nd field test confirm the estimation of the first field test that a realistic LOQ in the range of $0.1-0.3 \mu \mathrm{g} \mathrm{L}^{-1}$ during daily routine analysis of environmental samples from freshwaters can be achieved with the implemented CFA method. For the daytime variations of the measured free cyanide concentrations seen in the 2nd sampling campaign, no clear trend was observed and the concentration differences between the samplings at each site did not exceed the respective ranges of the measurement uncertainties.

\section{Conclusions and outlook}

Quantification of low free cyanide in samples from freshwater systems was successfully performed applying the slightly modified CFA method on an instrument equipped with a 50$\mathrm{cm}$ glass fiber cuvette. The achieved LOQs during the basic validation were in the range of $0.048-0.132 \mu \mathrm{g} \mathrm{L}^{-1}$ free cyanide.

According to the measurement of free cyanide in environmental samples, a reproducible LOQ of $0.1-0.3 \mu \mathrm{g} \mathrm{L}^{-1}$ can be obtained under realistic laboratory conditions. One LOQ of $0.461 \mu \mathrm{g} \mathrm{L}^{-1}$ shown in Table 1 is assumed to be an outlier.

The measurements prove that an LOQ for a potential compliance monitoring of free cyanide according to WFD requirements in concentrations of one order of magnitude below the 
Table 2 Free cyanide concentrations in samples from Esmecke Barrier Lake and river Lenne at different sampling sites during the two sampling campaigns of the $2 \mathrm{nd}$ field test (measured $24 \mathrm{~h}$ after sampling, stabilized at $\mathrm{pH} 12$, and stored at $4{ }^{\circ} \mathrm{C}$ in the dark)

\begin{tabular}{|c|c|c|c|c|c|c|c|}
\hline Sampling site & Time of day & $\operatorname{LOD}\left(\mu \mathrm{g} \mathrm{L}^{-1}\right)$ & $\operatorname{LOQ}\left(\mu \mathrm{g} \mathrm{L}^{-1}\right)$ & \multicolumn{2}{|c|}{$\begin{array}{l}\text { Measured free cyanide } \\
\text { concentration }\left(\mu \mathrm{g} \mathrm{L}^{-1}\right)\end{array}$} & $\begin{array}{l}\text { Reported free } \\
\text { cyanide concentration } \\
\left.(\mu \mathrm{g} \mathrm{L})^{-1}\right)^{\#}\end{array}$ & $\begin{array}{l}\text { Range of extended } \\
\text { measurement } \\
\text { uncertainty }( \pm)\end{array}$ \\
\hline \multicolumn{8}{|c|}{ 1st sampling campaign (October sampling, different day times) } \\
\hline \multirow[t]{3}{*}{ A } & Morning & 0.052 & 0.192 & 0.244 & 0.244 & 0.244 & 0.051 \\
\hline & Midday & 0.052 & 0.192 & 0.269 & 0.269 & 0.269 & 0.056 \\
\hline & Evening & 0.052 & 0.192 & 0.185 & $<\mathrm{LOQ}$ & 0.185 & 0.080 \\
\hline \multirow[t]{3}{*}{ B } & Morning & 0.029 & 0107 & 0.260 & 0.260 & 0.260 & 0.054 \\
\hline & Midday & 0.029 & 0107 & 0.228 & 0.228 & 0.228 & 0.047 \\
\hline & Evening & 0.029 & 0107 & 0.231 & 0.231 & 0.231 & 0.048 \\
\hline \multirow[t]{3}{*}{$\mathrm{C}$} & Morning & 0.022 & 0.081 & 0.161 & 0.161 & 0.161 & 0.034 \\
\hline & Midday & 0.022 & 0.081 & 0.192 & 0.192 & 0.192 & 0.040 \\
\hline & Evening & 0.022 & 0.081 & 0.157 & 0.157 & 0.157 & 0.033 \\
\hline \multirow[t]{3}{*}{ D } & Morning & 0.067 & 0.247 & $<$ LOQ & 0.123 & 0.123 & 0.054 \\
\hline & Midday & 0.067 & 0.247 & $<$ LOQ & 0.142 & 0.142 & 0.062 \\
\hline & Evening & 0.067 & 0.247 & $<$ LOQ & 0.117 & 0.117 & 0.051 \\
\hline \multicolumn{8}{|c|}{ 2nd sampling campaign (November sampling, only at midday) } \\
\hline A & Midday & 0.030 & 0.110 & 0.240 & 0.240 & 0.240 & 0.050 \\
\hline $\mathrm{B}$ & Midday & 0.030 & 0.110 & 0.204 & 0.204 & 0.204 & 0.042 \\
\hline $\mathrm{C}$ & Midday & 0.030 & 0.110 & 0.156 & 0.156 & 0.156 & 0.033 \\
\hline $\mathrm{D}$ & Midday & 0.030 & 0.110 & 0.174 & 0.174 & 0.174 & 0.036 \\
\hline
\end{tabular}

${ }^{\#}$ Concentrations < LOD were set to the respective LOD of the measurement series; for concentrations between LOD and LOQ, the measured concentrations are given

${ }^{\$}$ For concentrations below LOD, no measurement uncertainty could be calculated

current PNEC for freshwater organisms $\left(1 \mu \mathrm{g} \mathrm{L} \mathrm{L}^{-1}\right.$; ECHA (2020)) is achievable with the optimized CFA method presented here and the instrument with the 50-cm cuvette.

To test the implemented CFA method with real environmental samples, water from two field tests at a barrier lake and the river Lenne were taken for free cyanide analysis. Industry, which is working with cyanide, is not known to be located at the Esmecke Barrier Lake and the investigated stretch of the river Lenne. Both are in a rural area and expected to be uncontaminated. Concentrations in samples of the 1st field test during the winter/spring season were mostly below LOD or LOQ (Table 1) in contrast to most of the samples of the 2nd field test during the fall (Table 2). However, for concentrations between LOD and LOQ, the presence of free cyanide is confirmed in the sample but cannot be quantified reliably. Therefore, these values are given as the measured concentration \pm measurement uncertainty. The low free cyanide concentrations found were probably originating from environmental processes generating cyanide (Jaszczak et al. 2017) or atmospheric input (ECETOC 2007).

Implemented and validated here, and under field conditions tested, CFA method allows to quantify low amounts of free cyanide in freshwater systems for environmental monitoring at sub-PNEC concentrations with reliable measurements down to levels of about $0.1 \mu \mathrm{g} \mathrm{L}^{-1}$. Thus, the method can be applied for a possible WFD watch list monitoring of free cyanide as suggested by Loos et al. (2018). However, in order to allow an assessment of the generated monitoring data, it is necessary to reliably determine relevant natural impact factors on free cyanide background concentrations in different water bodies, like season, climate, geology, light exposure, and water depths or other water body characteristics. Such data on environmental free cyanide levels will form the inevitable basis for a valid differentiation of anthropogenic pollution from natural fluctuations.

Supplementary Information The online version contains supplementary material available at https://doi.org/10.1007/s11356-020-12062-7.

Acknowledgments The initiation of this project by Cefic, CONCAWE, Eurofer, and Euromines is gratefully acknowledged. A. DominguezPerez and D. Bertow are thanked for their support of the project.

Authors' contributions All authors contributed to the study conception and design. Method implementation and optimization, analysis, and data evaluation were performed by DH and BK. The first draft of the manuscript was written by TK and HR and all authors commented on previous versions of the manuscript. All authors read and approved the final submitted manuscript. 
Funding Open Access funding enabled and organized by Projekt DEAL. This project was initiated and funded by Cefic, CONCAWE, Eurofer, and Euromines.

Data availability The datasets supporting the conclusions of this article are included within the article and its additional file.

\section{Compliance with ethical standards}

Conflict of interest The authors declare that they have no conflict of interest.

Ethical approval Not applicable.

Consent to participate Not applicable.

\section{Consent to publish Not applicable.}

Open Access This article is licensed under a Creative Commons Attribution 4.0 International License, which permits use, sharing, adaptation, distribution and reproduction in any medium or format, as long as you give appropriate credit to the original author(s) and the source, provide a link to the Creative Commons licence, and indicate if changes were made. The images or other third party material in this article are included in the article's Creative Commons licence, unless indicated otherwise in a credit line to the material. If material is not included in the article's Creative Commons licence and your intended use is not permitted by statutory regulation or exceeds the permitted use, you will need to obtain permission directly from the copyright holder. To view a copy of this licence, visit http://creativecommons.org/licenses/by/4.0/.

\section{References}

Australian Water Association (2000) National water quality management strategy, Aquatic Ecosystems. Rationale and Background Information (Chapter 8) vol 2. Australian and New Zealand Guidelines for Fresh and Marine Water Quality. Artarmon, https:// www.waterquality.gov.au/sites/default/files/documents/anzeccarmcanz-2000-guidelines-vol2.pdf

DIN (2008) DIN 32645:2008-11 (German version) Chemical analysisdecision limit, detection limit and determination limit under repeatability conditions-terms, methods, evaluation

EC (2009) Comission Directive 2009/90/EC of 31 July 2009 laying down, pursuant to Directive 2000/60/EC of the European Parliament and of the Council, technical specifications for chemical analysis and monitoring of water status (QA/QC-Directive). Official Journal of the European Union L 201/36-38, https://eur-lex.europa. eu/LexUriServ/LexUriServ.do?uri=OJ:L:2009:201:0036:0038:EN: PDF

ECETOC (2007) Cyanides of hydrogen, sodium and potassium, and acetone cyanohydrin (CAS No. 74-90-8, 143-33-9, 151-50-8 and 75-86-5). ECETOC Joint Assessment of Commodity Chemicals Report Volume 1. ISSN-0773-6339-53. Brussels, Belgium, September 2007. www.ecetoc.org/publication/jacc-report-53cyanides-of-hydrogen-sodium-and-potassium-and-acetonecyanohydrin-vol-ii/

ECHA (2020) REACh dossier Sodium Cyanide, CAS number 143-33-9. Registration Dossier, Part: Ecotoxicological Summary. https://echa. europa.eu/de/registration-dossier/-/registered-dossier/15159/6/1

EU (2013) Directive 2013/39/EU of the European Parliament and of the Council of 12 August 2013 amending Directives 2000/60/EC and
2008/105/EC as regards priority substances in the field of water policy vol 2013/39, 24 Aug. 2013 edn. Official Journal of the European Communities, https://publications.europa.eu/en/ publication-detail/-/publication/296e91b8-4610-11e3-ae0301aa75ed71a1/language-en

EU (2015a) Commission Implementing Decision (EU) 2015/495 of 20 March 2015 establishing a watch list of substances for Union-wide monitoring in the field of water policy pursuant to Directive 2008/105/EC of the European Parliament and of the Council. vol 2015/495. Official Journal of the European Union, https://eur-lex. europa.eu/legal-content/EN/TXT/PDF/?uri=CELEX: 32015D0495\&from=EN

EU (2015b) Free cyanides. Draft EQS dossier. Prepared by JRC for the EU Commission. June 30, 2015 https://circabc.europa.eu/d/a/ workspace/SpacesStore/7b326d79-9b29-41e2-bff7-d49ab9ade68a/ Summary\%20dossier\%20review\%20Cyanides-DRAFT-JRC2015 v3.docx

Geiss S, Einax JW (2001) Comparison of detection limits in environmental analysis-is it possible? An approach on quality assurance in the lower working range by verification Fresenius' journal of analytical chemistry 370:673-678

ISO (2007) ISO 11885:2007. Water quality-determination of selected elements by inductively coupled plasma optical emission spectrometry (ICP-OES). German version: DIN EN ISO 11885:2009

ISO (2012) ISO 14403-2:2012 Water quality-determination of total cyanide and free cyanide using flow analysis (FIA and CFA) - Part 2: Method using continuous flow analysis (CFA). German version EN ISO 14403-2:2012

ISO/IEC (2005) ISO/IEC 17025:2005. General requirements for the competence of testing and calibration laboratories. German version DIN ISO/IEC 17025:2005

Jaszczak E, Polkowska Ż, Narkowicz S, Namieśnik J (2017) Cyanides in the environment-analysis-problems and challenges Environmental science and pollution research international 24:15929-15948 doi: https://doi.org/10.1007/s11356-017-9081-7

Krutz H (1981) Different origins of cyanide concentration in small rivers. In: Vennesland B, Conn EE, Knowles J, Wissing F (eds) Cyanide in biology. Academic Press, London, UK, pp 479-485

Loos R, Marinov D, Sanseverino I, Napierska D, Lettieri T (2018) Review of the 1 st Watch List under the Water Framework Directive and recommendations for the 2nd Watch List. April 2018 JRC, https://publications.jrc.ec.europa.eu/repository/ bitstream/JRC111198/wl_report_jrc_2018_04_26_final_online.pdf

Ma J, Dasgupta PK (2010) Recent developments in cyanide detection: a review Analytica Chimica Acta 673:117-125 doi:https://doi.org/10. 1016/j.aca.2010.05.042

Maranna MC, Saikrishnan LM, Dinesh TK, Tyagi KK (2018) Determination of hydrogen cyanide in cigarette smoke by Continuous Flow Analysis method using safer chemistry. Contributions to Tobacco Research 28: 191-202 doi:https://doi. org/10.2478/cttr-2018-0018

Magnusson B, Näykki T, Hovind H, Krysell M (2012) Handbook for calculation of measurement uncertainty in environmental laboratories. Nordic Innovation, Oslo http://www.nordtest.info/images/ documents/nt-technical-reports/nt tr 537 ed 31 English Handbook $\% 20$ for $\% 20$ Calculation $\overline{2} 20$ of $\% \overline{2} 0$ Measurement $\overline{\%}$ 20uncertainty\%20in\%20environmental\%20laboratories.pdf

Peters A, Leverett D, Wilson I, Moore C, Merrington G (2012) EQS proposal for free cyanid. Report for the European Commission by wca environment limited, Oxfordshire, UK. https://circabc.europa. eu/webdav/CircaBC/env/wfd/Library/working groups/priority substances/1a\%20-\%20WG\%20Chemicals\%20Meetings/WG\% 20Chemicals\%202014-10-16-17/Documents\%20after\%20the\% 20meeting/Cyanides\%20EQS\%20Draft\%20Report_wca.pdf 
Skalar Analytical (2015) SAN++ method: analysis of free disillable cyanide in surface water . Catnr. I295-003w/r issue 031915/MH/ 99295930. Skalar Analytical B.V., Breda, The Netherlands

Sorokin N, Atkinson C, Aldous E, Rule K, Maycock D, Comber S (2012) Proposed EQS for Water Framework Directive Annex VIII substances: cyanide (free). For consultation. Water Framework Directive - United Kingdom Technical Advisory Group (WFD-
UKTAG) https://www.wfduk.org/sites/default/files/Media/ Environmental\%20standards/Cyanide_Final_.pdf.s

Publisher's note Springer Nature remains neutral with regard to jurisdictional claims in published maps and institutional affiliations. 